\title{
Mechanism of the hydrodenitrogenation of neopentylamine and adamantylamine on sulfided $\mathrm{NiMo} / \mathrm{Al}_{2} \mathrm{O}_{3}$
}

\author{
Y. Zhao, ${ }^{\mathrm{a}, \mathrm{b}}$ N. Sivasankar, ${ }^{\mathrm{a}}$ J. Czyzniewska, ${ }^{\mathrm{a}, \mathrm{c}}$ P. Kukula, ${ }^{\mathrm{a}}$ and R. Prins ${ }^{\mathrm{a}, *}$ \\ ${ }^{a}$ Institute for Chemical and Bioengineering, ETH Zurich, 8093 Zurich, Switzerland \\ ${ }^{b}$ Hereaus Chemicals Division, 63450 Hanau, Germany \\ ${ }^{c}$ Biofarm Sp., 60-198 Poznan, Poland
}

Received 16 April 2006; accepted 11 June 2006

\begin{abstract}
Neopentanethiol, 1-adamantanethiol, and 2-adamantanethiol were primary products and neopentane and adamantane were secondary products in the hydrodenitrogenation of neopentylamine, 1-adamantylamine, and 2-adamantylamine, respectively, over sulfided $\mathrm{NiMo} / \mathrm{Al}_{2} \mathrm{O}_{3}$. Dialkylamines and dialkylimines were formed as primary products in the reactions of 2-adamantylamine and neopentylamine as well. None of the three amines can react by ammonia elimination and a classic $\mathrm{S}_{\mathrm{N}} 2$ substitution of the $\mathrm{NH}_{2}$ group by $\mathrm{H}_{2} \mathrm{~S}$ is not possible for the adamantylamines either. The formation of di(2-adamantyl)imine and di(neopentyl)imine indicates that dehydrogenation and hydrogenation reactions occur and that imine or iminium-cation intermediates play an important role. $\mathrm{NH}_{2}$-SH substitution takes place by dehydrogenation of the amine to an imine or iminium cation, which adds $\mathrm{H}_{2} \mathrm{~S}$ and eliminates $\mathrm{NH}_{3}$. The secondary character of adamantane and neopentane demonstrates that hydrogenolysis of the aliphatic $\mathrm{C}-\mathrm{N}$ bond does not take place over sulfided $\mathrm{NiMo} / \mathrm{Al}_{2} \mathrm{O}_{3}$ below $340{ }^{\circ} \mathrm{C}$. Even though 1-adamantylamine can neither react by classic $\mathrm{S}_{\mathrm{N}}$ 2, E1, and $\mathrm{E} 2$ reactions, nor via an imine or iminium cation, it formed 1-adamanethiol at $300{ }^{\circ} \mathrm{C}$. This reaction might take place by an $\mathrm{S}_{\mathrm{N}} 1$ reaction or by adsorption of the amine at a surface vacancy, followed by a shift of the adamantyl group to a neighboring sulfur atom.
\end{abstract}

KEY WORDS: adamantylamine; adamantanethiol; neopentylamine; HDN; mechanism; hydrotreating catalysts; hydrogenolysis.

\section{Introduction}

The cleavage of a carbon-sulfur $(\mathrm{C}-\mathrm{S})$ or a carbonnitrogen $(\mathrm{C}-\mathrm{N})$ bond is the final step in hydrodesulfurization (HDS) or hydrodenitrogenation (HDN) reactions. $\mathrm{C}-\mathrm{S}$ bond cleavage may occur by elimination as well as by homolytic $\mathrm{C}-\mathrm{S}$ bond scission (hydrogenolysis), as demonstrated in the HDS of alkanethiols [13] and aromatic thiols such as benzothiophene and dibenzothiophene [4,5]. C-S hydrogenolysis has also been observed in the homogeneous reaction of aliphatic and aromatic thiols to hydrocarbons with the $\mathrm{Cp}_{2}{ }_{2} \mathrm{Mo}_{2} \mathrm{Co}_{2} \mathrm{~S}_{3}(\mathrm{CO})_{4}$ cluster [6].

The $\mathrm{C}-\mathrm{N}$ bond in aromatic molecules like pyridine can only be broken after hydrogenation of the aromatic heterocycle [7-9]. Even the removal of ammonia from exocyclic aromatic amines such as aniline takes place mainly after hydrogenation of the aniline to cyclohexylamine. Less than $10 \%$ occurs by hydrogenolysis to benzene [8-10] and this hydrogenolysis of the aryl $\mathrm{C}-\mathrm{N}$ bond is only apparent [11]. In reality the breaking of the aryl $\mathrm{C}-\mathrm{N}$ bond takes place by partial hydrogenation of the arylamine. For aniline it occurs by hydrogenation to 1,2-dihydroaniline and elimination of the $\mathrm{NH}_{2}$ group to form benzene. This $\mathrm{NH}_{2}$ elimination is of the E1 type,

*To whom correspondence should be addressed. E-mail: roel.prins@chem.ethz.ch (R. Prins) because the empty $2 p_{z}$ orbital on the carbon atom in the resulting carbocation is conjugated with double bonds [11].

Aliphatic $\mathrm{C}-\mathrm{N}$ bond breaking has been claimed to occur by elimination $[7,12]$ and by nucleophilic substitution by $\mathrm{H}_{2} \mathrm{~S}$ followed by $\mathrm{C}-\mathrm{S}$ bond hydrogenolysis $[7,13]$. In the past years, we showed that for amines with the amine group attached to a primary and secondary carbon atom $\mathrm{C}-\mathrm{N}$ bond breaking occurs predominantly by the nucleophilic substitution pathway $[3,14,15]$. Only when the amine group is attached to a tertiary carbon atom, or to an activated carbon atom as in benzylamine, does elimination of ammonia occur. The nucleophilic substitution does not take place by a classic organic reaction, but by a series of metal-like reactions: dehydrogenation of the amine to an imine, addition of $\mathrm{H}_{2} \mathrm{~S}$, elimination of $\mathrm{NH}_{3}$, and hydrogenation of the resulting thioaldehyde to a thiol [16].

Although the $\mathrm{C}-\mathrm{N}$ bond in aliphatic amines is weaker than in arylamines, alkanes were not observed as primary products in the reaction of alkylamines $[3,14,15]$. The hydrogenolysis of alkylamines might be masked by other, faster reactions, however. To investigate if hydrogenolysis is possible for alkylamines, we studied the removal of ammonia from 1-adamantylamine, 2-adamantylamine, and neopentylamine (2,2-dimethylpropylamine). These molecules hardly have other possibilities to react than by 
hydrogenolysis of the aliphatic $\mathrm{C}-\mathrm{N}$ bond. 1-Adamantylamine has the amino group at a carbon bridgehead and can, therefore, not react via elimination or via $\mathrm{S}_{\mathrm{N}} 2$ substitution and an $\mathrm{S}_{\mathrm{N}} 1$ reaction does not seem logical [17,18]. 2-Adamantylamine cannot react by elimination either, and because $\mathrm{S}_{\mathrm{N}} 1$ and $\mathrm{S}_{\mathrm{N}} 2$ substitution are unlikely, hydrogenolysis would be a good possibility to react. The same holds for neopentylamine. The lack of a $\beta$-hydrogen atom makes elimination impossible, the heavy substitution at the $\beta$-carbon atom hinders $\mathrm{S}_{\mathrm{N}} 2$ substitution at the $\alpha$-carbon atom very much, and $\mathrm{S}_{\mathrm{N}} 1$ substitution is unlikely at a primary carbon atom $[17,18]$.

\section{Experimental}

The catalytic experiments were carried out in a microflow reactor. The $\mathrm{NiMo} / \mathrm{Al}_{2} \mathrm{O}_{3}$ catalyst was prepared by sequential pore volume impregnation of $\gamma-\mathrm{Al}_{2} \mathrm{O}_{3}$, sulfided in situ, and directly used thereafter, without exposing to nitrogen or air; as described before [3]. The total pressure was $3 \mathrm{MPa}$ in all experiments, the partial pressure of neopentylamine was $5 \mathrm{kPa}$, and the partial pressures of the adamantylamines and 1 -adamantanethiol were kept at $1 \mathrm{kPa}$ to avoid condensation. The experiments were carried out at 300 and $340{ }^{\circ} \mathrm{C}$ with a partial pressure of $\mathrm{H}_{2} \mathrm{~S}$ of 10 and $100 \mathrm{kPa}$.
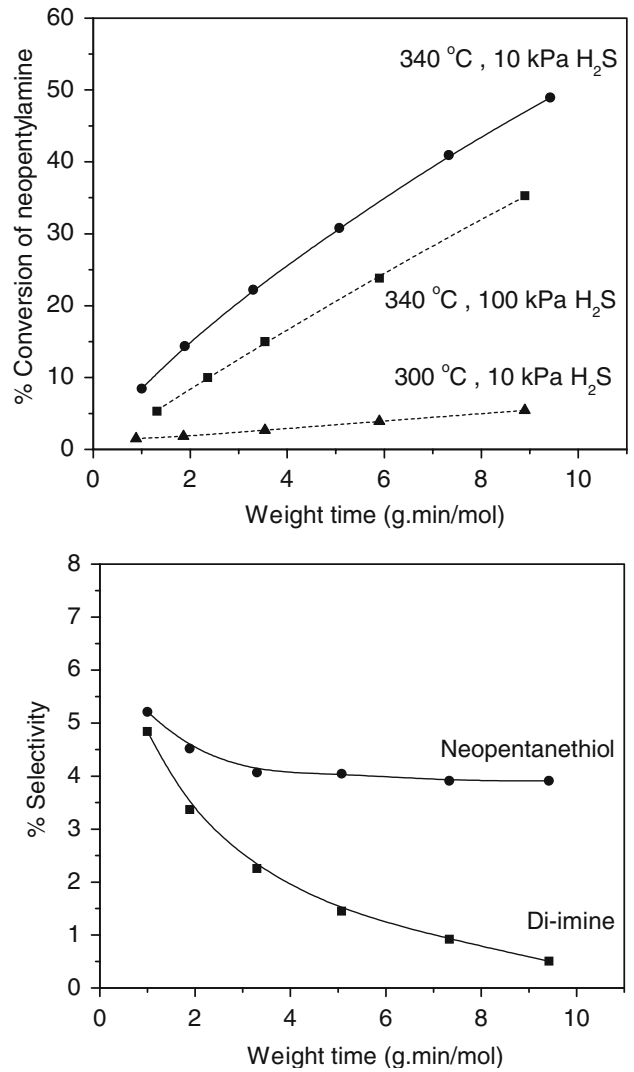

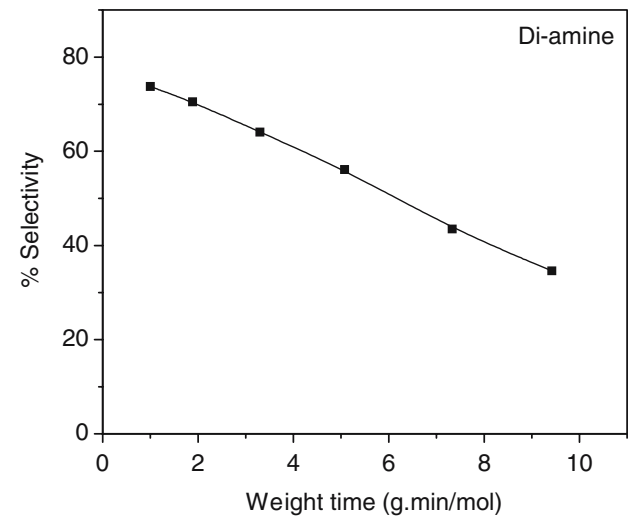

1-Adamantylamine (Aldrich, pract.), 2-adamantylamine (Fluka, purum), 1-adamantanethiol (Apin Chemicals Limited), adamantane (Fluka, purum), neopentylamine (TCI, purum), and octane (Across, puriss.) were all used as received. The gases used were hydrogen (PanGas 4.0) and a mixture of $10 \% \mathrm{H}_{2} \mathrm{~S}$ in $\mathrm{H}_{2}$ (Messer Griesheim 3.0). For the purpose of solubility, all reactants were dissolved in decane. The products dineopentylamine, dineopentylimine, di(2-adamantyl)amine, and di(2-adamantyl)imine are not commercially available and therefore their qualitative analysis was based on GC separation and MS analysis. Their quantitative $\mathrm{GC}$ analysis was based on response factors based on the number of carbon atoms. As a consequence, the conversions and selectivities in the HDN of neopentylamine and 2-adamantylamine should be treated semi-quantitatively.

\section{Results}

\subsection{Neopentylamine}

The conversion of neopentylamine was very low at $300{ }^{\circ} \mathrm{C}$ in the presence of $10 \mathrm{kPa} \mathrm{H}_{2} \mathrm{~S}$, only about $4 \%$ at the high weight time of $\tau=9 \mathrm{~g} \mathrm{~min} / \mathrm{mol}$ and reliable product yield data were difficult to obtain. To increase the product yields, the temperature was therefore

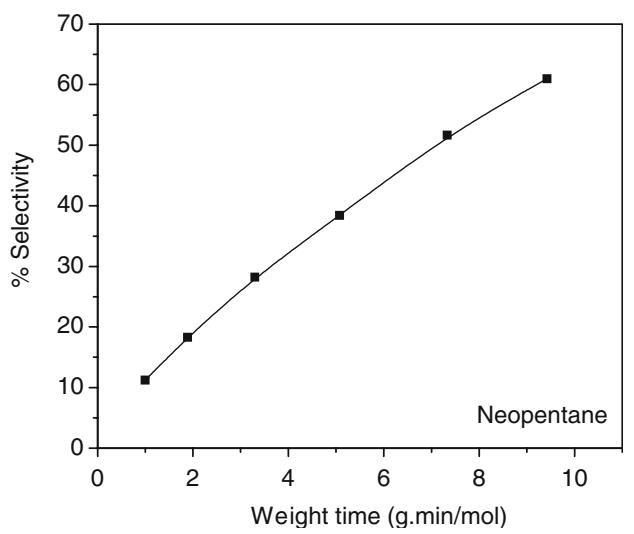

Figure 1. Conversions at 300 and $340{ }^{\circ} \mathrm{C}$ and product selectivities at $340{ }^{\circ} \mathrm{C}$ in the $\mathrm{HDN}$ of neopentylamine in the presence of $10 \mathrm{kPa} \mathrm{H}_{2} \mathrm{~S}$. 
increased to $340{ }^{\circ} \mathrm{C}$. At this temperature the conversion was much higher, $50 \%$ at $\tau=9.3 \mathrm{~g} \mathrm{~min} / \mathrm{mol}$ (figure 1). The conversion decreased slightly when increasing the $\mathrm{H}_{2} \mathrm{~S}$ pressure from 10 to $100 \mathrm{kPa}$. Neopentylamine reacted to 2,2-dimethylpropane (neopentane), 2,2-dimethylpropanethiol (neopentanethiol), dineopentylamine, and dineopentylimine (figure 1). Neopentanethiol, dineopentylamine, and dineopentylimine were primary products, because their selectivities were non-zero at $\tau=0$, while neopentane behaved as a secondary product because its selectivity started at zero at $\tau=0$.

\subsection{Adamantylamines and adamantanethiol}

1-Adamantylamine $\left(1-\mathrm{AdNH}_{2}\right)$ had a high conversion at $300{ }^{\circ} \mathrm{C}$ in the presence of $10 \mathrm{kPa} \mathrm{H}_{2} \mathrm{~S}$ and even higher at $100 \mathrm{kPa} \mathrm{H}_{2} \mathrm{~S}$ pressure (figure 2). Only two products were observed, adamantane and 1-adamantanethiol (1-AdSH); no isomerization products $\left(2-\mathrm{AdNH}_{2}\right.$ and 2-AdSH) were observed. The selectivity to 1-AdSH increased strongly with decreasing $\tau$, indicating that 1AdSH is the primary product of the $\mathrm{HDN}$ of $1-\mathrm{AdNH}_{2}$, which reacted further to adamantane as a secondary product.

The thiol 1-AdSH reacted much faster than the amines 1- $\mathrm{AdNH}_{2}$ and $2-\mathrm{AdNH}_{2}$ in the presence of $10 \mathrm{kPa} \mathrm{H}_{2} \mathrm{~S}$ and $1 \mathrm{kPa}$ hexylamine and reached almost complete conversion at $\tau=3 \mathrm{~g} \mathrm{~min} / \mathrm{mol}$ (figure 2). Hexylamine was added to simulate the presence of an alkylamine during the reaction of the alkanethiol and thus mimic its inhibiting effect on the HDS. Adamantane was the only product in the reaction of 1-AdSH.

2- $\mathrm{AdNH}_{2}$ reacted to 2-AdSH and adamantane, as well as to di(2-adamantyl)amine and di(2-adamantyl)imine at $300{ }^{\circ} \mathrm{C}$ and $10 \mathrm{kPa} \mathrm{H}_{2} \mathrm{~S}$ (figure 3). At the higher $\mathrm{H}_{2} \mathrm{~S}$ pressure of $100 \mathrm{kPa}$ the conversion increased slightly and the selectivity to di(2-adamantyl)amine and $\operatorname{di}(2-$ adamantyl)imine was suppressed to $8 \%$ at $\tau=1.6 \mathrm{~g} \mathrm{~min} /$ mol.

\section{Discussion}

\subsection{HDN of neopentylamine}

Neopentylamine has no $\beta-\mathrm{H}$ atoms and Hofmann elimination can therefore not take place [12]. In an $S_{N} 1$ reaction a primary carbenium ion has to be formed. This is highly unlikely, as also demonstrated by the fact that no rearrangement products such as methylbutane or methylbutene were observed in the HDN of neopentylamine. Such Wagner-Meerwein-type rearrangement products (2,3-dimethylbutane and 2,3-dimethylbutenes) were observed in the HDN of 3,3-dimethyl-2-butyl-
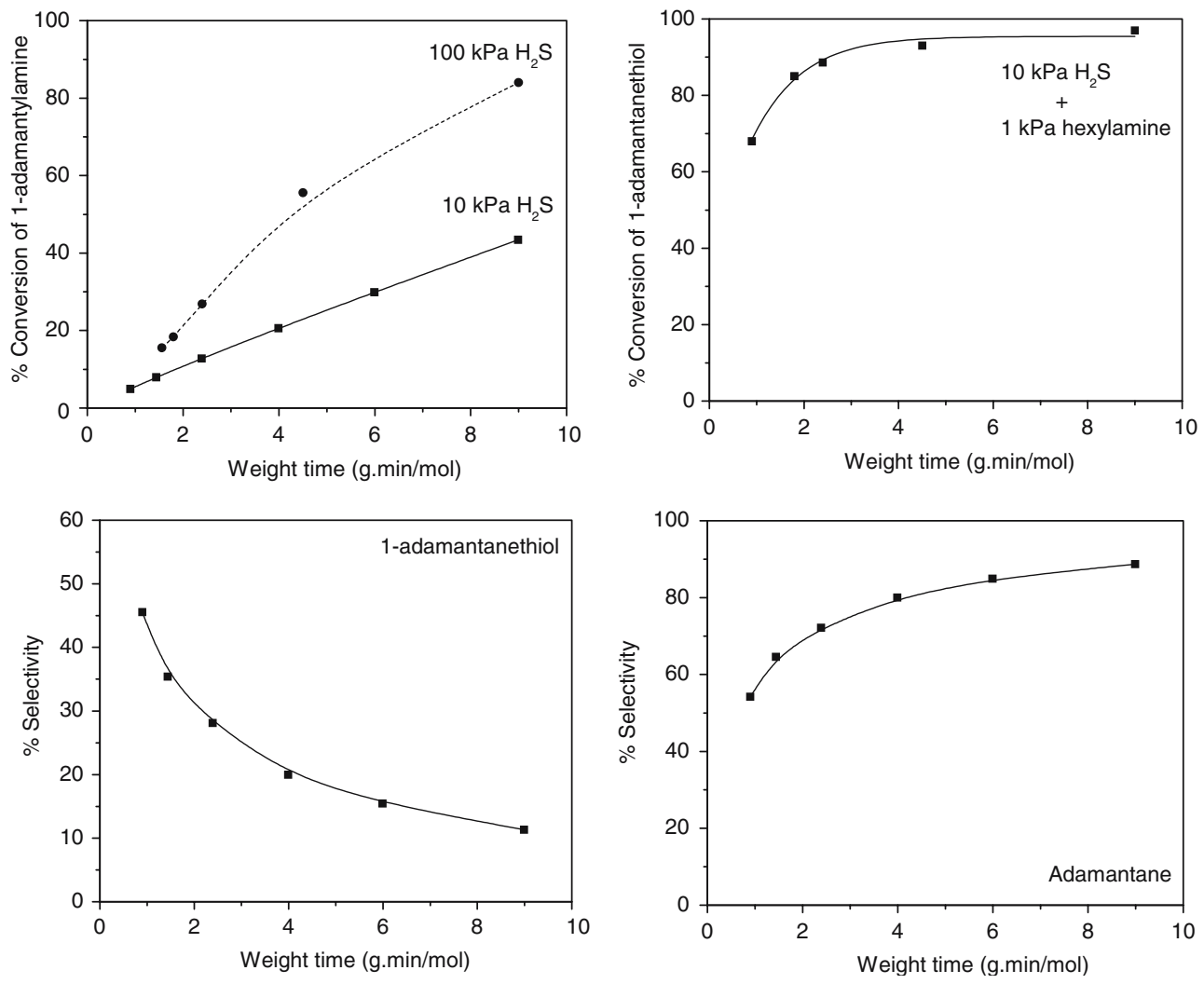

Figure 2. Conversion of 1-adamantylamine at $300{ }^{\circ} \mathrm{C}$ and 10 and $100 \mathrm{kPa} \mathrm{H}_{2} \mathrm{~S}$ and product selectivities at $300{ }^{\circ} \mathrm{C}$ and $10 \mathrm{kPa} \mathrm{H}_{2} \mathrm{~S}$, as well as conversion of 1-adamantanethiol at $300{ }^{\circ} \mathrm{C}$ and $10 \mathrm{kPa} \mathrm{H}_{2} \mathrm{~S}$ and $1 \mathrm{kPa}$ hexylamine. 

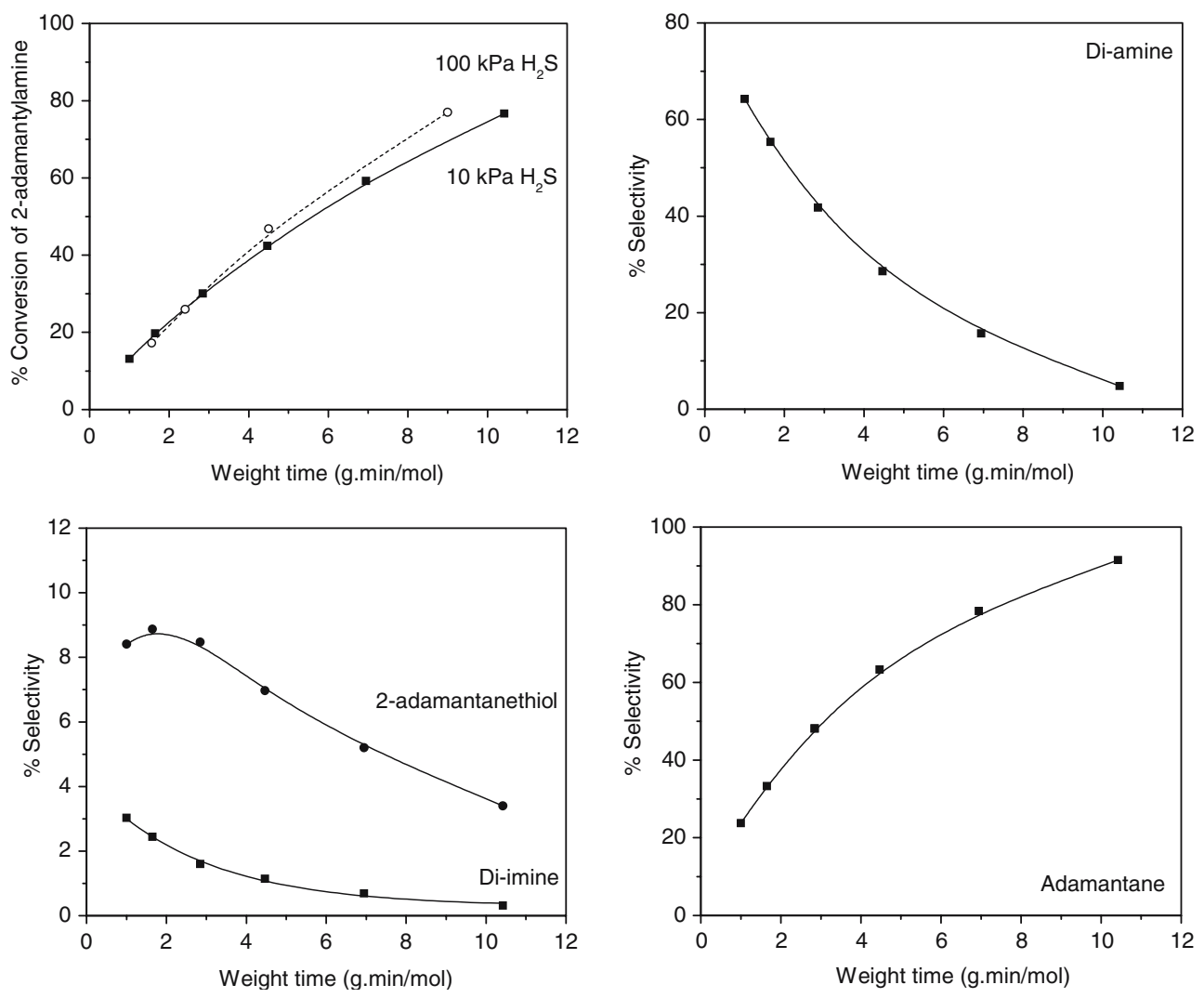

Figure 3. Conversion of 2-adamantylamine at $300{ }^{\circ} \mathrm{C}$ and 10 and $100 \mathrm{kPa} \mathrm{H}_{2} \mathrm{~S}$ and product selectivities at $300{ }^{\circ} \mathrm{C}$ and $10 \mathrm{kPa} \mathrm{H}_{2} \mathrm{~S}$.

amine [14]. Thus, neopentylamine can only react by $\mathrm{S}_{\mathrm{N}} 2$ substitution or hydrogenolysis.

Portefaix et al. already reported that neopentylamine hardly reacted at $270{ }^{\circ} \mathrm{C}$ [12]. Our results show that even at $300{ }^{\circ} \mathrm{C}$ neopentylamine reacts very slowly and that an appreciable conversion $(22 \%$ at $\tau=3.3 \mathrm{~g} . \mathrm{min} / \mathrm{mol})$ is only obtained at $340{ }^{\circ} \mathrm{C}$ (figure 1). The main products were neopentanethiol, dineopentylamine, dineopentylimine, and neopentane. Neopentane is a secondary and not a primary product. This demonstrates that hydrogenolysis of neopentylamine to neopentane does not occur below $340{ }^{\circ} \mathrm{C}$. Apparently hydrogenolysis of an aliphatic $\mathrm{C}-\mathrm{N}$ bond is difficult over a metal sulfide catalyst. In contrast, $\mathrm{C}-\mathrm{N}$ bond hydrogenolysis over metal catalysts is an easy reaction [19], for instance on supported platinum it is already fast at $150{ }^{\circ} \mathrm{C}$ [20]. Amines with a primary $\alpha$-carbon atom react much faster on $\mathrm{Pt}$ than amines with a secondary $\alpha$-carbon atom, which react again about an order of magnitude faster than amines with a tertiary $\alpha$-carbon atom. Hydrogenolysis of the $\mathrm{C}-\mathrm{N}$ bond is assumed to take place after adsorption of both neighboring $\mathrm{N}$ and $\mathrm{C}$ atoms on the catalyst surface. Substitution on the $\alpha-\mathrm{C}$ atom makes adsorption of this $\alpha-\mathrm{C}$ atom difficult, thus decreasing the rate of hydrogenolysis. This reactivity pattern on $\mathrm{Pt}$ is opposite to that observed for the alkylamines on sulfided $\mathrm{NiMo} /$ $\mathrm{Al}_{2} \mathrm{O}_{3}$, where the reactivity order is 2-methyl-2-butylamine $\gg 2$-pentylamine $>1$-pentylamine confirming that HDN on metal sulfides occurs by a different mechanism than on metals.

The low reactivity of neopentylamine is easy to understand. Hofmann elimination is impossible, $\mathrm{S}_{\mathrm{N}} 1$ substitution is unlikely, and hydrogenolysis does not take place. The occurrence of neopentanethiol, dineopentylamine, and dineopentylimine as primary products indicates that substitution of neopentylamine by $\mathrm{H}_{2} \mathrm{~S}$ and by neopentylamine are responsible for the formation of neopentanethiol and dineopentylamine, respectively. The secondary nature of neopentane indicates that the majority of neopentane is formed from neopentanethiol by $\mathrm{C}-\mathrm{S}$ hydrogenolysis. This is in agreement with the fast reaction of alkanethiols by elimination to alkenes and by hydrogenolysis to alkanes [3], and with the fast reaction of 1-AdSH (section 3.2). The tertiary butyl group at the $\alpha$-carbon atom of neopentylamine hinders substitution [17] and neopentylamine therefore reacts much slower than the nonbranched $n$-pentylamine [15].

The substitution of an alkylamine by another alkylamine or by $\mathrm{H}_{2} \mathrm{~S}$ over metal sulfide catalysts occurs by a sequence of dehydrogenation-additionelimination-hydrogenation reactions. This was inferred from the steric course of the HDN of 2-(S)-butylamine to 2-butanethiol and di-sec-butylamine at $3 \mathrm{MPa}$ and $300{ }^{\circ} \mathrm{C}$ over sulfided $\mathrm{NiMo} / \gamma-\mathrm{Al}_{2} \mathrm{O}_{3}$. It showed that the 2-butanethiol product was completely racemic, that the 


\section{Imine intermediate}

$$
\begin{aligned}
& \mathrm{RCH}_{2}-\mathrm{NH}_{2} \rightarrow \mathrm{RCH}=\mathrm{NH}+\mathrm{H}_{2} \\
& \mathrm{H}_{2} \mathrm{Y}+\mathrm{RCH}=\mathrm{NH} \rightarrow \mathrm{HY}-\mathrm{CHR}-\mathrm{NH}_{2} \\
& \mathrm{HY}-\mathrm{CHR}-\mathrm{NH}_{2} \rightarrow \mathrm{Y}=\mathrm{CHR}+\mathrm{NH}_{3} \\
& \mathrm{Y}=\mathrm{CHR}+\mathrm{H}_{2} \rightarrow \mathrm{HY}-\mathrm{CH}_{2} \mathrm{R}
\end{aligned}
$$

\section{Iminium-cation intermediate}

$$
\begin{aligned}
& \mathrm{RCH}_{2}-\mathrm{NH}_{2} \rightarrow \mathrm{RCH}=\mathrm{NH}_{2}^{+}+\mathrm{H}^{+}+2 \mathrm{e} \\
& \mathrm{H}_{2} \mathrm{Y}+\mathrm{RCH}=\mathrm{NH}_{2}^{+} \rightarrow \mathrm{HY}-\mathrm{CHR}-\mathrm{NH}_{3}^{+} \\
& \mathrm{HY}-\mathrm{CHR}-\mathrm{NH}_{3}^{+} \rightarrow \mathrm{HY}^{+}=\mathrm{CHR}+\mathrm{NH}_{3} \\
& \mathrm{HY}^{+}=\mathrm{CHR}+\mathrm{H}_{2} \rightarrow \mathrm{HY}^{-} \mathrm{CH}_{2} \mathrm{R}+\mathrm{H}^{+}
\end{aligned}
$$

Scheme 1. Substitution of the amine group of an alkylamine by an alkylamine $\left(\mathrm{H}_{2} \mathrm{Y}=\mathrm{RC} \mathrm{H}_{2}-\mathrm{NH}_{2}\right)$ or thiol group $\left(\mathrm{H}_{2} \mathrm{Y}=\mathrm{H}_{2} \mathrm{~S}\right)$ by means of an imine or iminium-cation intermediate.

di-sec-butylamine product consisted mainly of $(R, S)$-disec-butylamine, and that racemization of the reacting 2-(S)-butylamine had partly taken place [16]. Two, slightly different, mechanisms can explain all products and their configurations as well as the racemization of the amine reactant. In one mechanism the alkylamine first reacts by dehydrogenation to an imine, while in the other mechanism the alkylamine first reacts by electron and proton transfer to an imine cation (Scheme 1). Thereafter, the addition of $\mathrm{H}_{2} \mathrm{~S}$ or an amine molecule to the imine or to the imine cation takes place and, after ammonia elimination and hydrogenation, an alkanethiol or a dialkylamine is formed.

Recently it was found that the probability of breaking the $\mathrm{C}_{1}-\mathrm{N}$ bond of $\mathrm{C}_{1}-\mathrm{NH}-\mathrm{C}_{6}$ and $\mathrm{C}_{1}-\mathrm{N}\left(\mathrm{C}_{6}\right)_{2}$ was similar to that of breaking the $\mathrm{C}_{6}-\mathrm{N}$ bond, while the reaction of $\mathrm{C}_{5}-\mathrm{NH}-\mathrm{C}_{5}$ and $\mathrm{C}_{1}-\mathrm{N}\left(\mathrm{C}_{6}\right)_{2}$ gave $\mathrm{C}_{1}-$ $\mathrm{N}\left(\mathrm{C}_{5}\right)_{2}$ as well as $\mathrm{C}_{6}-\mathrm{N}\left(\mathrm{C}_{5}\right)_{2}$ [21]. The transfer of the methyl group in these reactions cannot be explained by imine or enamine intermediates, only an iminium-cation intermediate can explain it. This suggests that all alkylamines react through iminium-cation intermediates (Scheme 1). This scheme also explains the formation of dineopentylamine, dineopentylimine, and neopentanethiol. The occurrence of dineopentylimine is in good agreement with this mechanism and its high initial selectivity is due to the high degree of substitution of the dialkylimine which hinders the hydrogenation to the dialkylamine.

\section{2. $\mathrm{HDN}$ of 2- $\mathrm{AdNH}_{2}$}

The sulfided $\mathrm{NiMo} / \mathrm{Al}_{2} \mathrm{O}_{3}$ catalyzes the removal of the $\mathrm{NH}_{2}$ group from 2-adamantylamine. Hofmann elimination is impossible for this molecule because a bridgehead double bond as in adamantene is highly strained and will therefore not form easily, as expressed in Bredt's rule [17]. Adamantene has been synthesized by irradiation of diazo compounds, but its lifetime is extremely short [22]. The selectivity pattern of the HDN of 2-adamantylamine at $300{ }^{\circ} \mathrm{C}$ (figure 3 ) was similar to that of neopentylamine at $340{ }^{\circ} \mathrm{C}$ (figure 1). Di(2-adamantyl)amine, di(2-adamantyl)imine, and 2-adamantanethiol were primary products and adamantane was a secondary product. The initial selectivities of di(2-adamantyl)amine and di(2-adamantyl)imine were much higher than that of the thiol. At $340{ }^{\circ} \mathrm{C}$ the situation is reversed (not shown), most probably because di(2-adamantylamine) and di(2-adamantylimine) react very fast with $\mathrm{H}_{2} \mathrm{~S}$ to 2-adamantanethiol.

The selectivity of 2-adamantanethiol shows a maximum at short weight time. The formation of 2-adamantanethiol by a primary reaction of the alkylamine with $\mathrm{H}_{2} \mathrm{~S}$ (Scheme 2), followed by reaction of the thiol to adamantane, would lead to a continuously decreasing thiol selectivity. The initial increase of the 2-adamantanethiol selectivity is thus proof for the presence of a secondary reaction between $\mathrm{H}_{2} \mathrm{~S}$ and the initially formed di(2-adamantyl)amine and di(2-adamantyl)imine (Scheme 2). The secondary reaction is in agreement with the high initial selectivities of di(2-adamantyl)amine and di(2-adamantyl)imine at $300{ }^{\circ} \mathrm{C}$ and with the much higher reactivity of dihexylamine than hexylamine with $\mathrm{H}_{2} \mathrm{~S}$ [3]. The higher rate of the primary reaction at $340{ }^{\circ} \mathrm{C}$ than at $300{ }^{\circ} \mathrm{C}$ explains why at $340{ }^{\circ} \mathrm{C}$ 2-adamantanethiol seems to be formed as a primary product only.

2-Adamantylamine and di(2-adamantyl)amine can neither react with $\mathrm{H}_{2} \mathrm{~S}$ by a classic $\mathrm{S}_{\mathrm{N}} 1$ reaction nor by an $S_{N} 2$ reaction [23,24]. An $S_{N} 1$ mechanism is ruled out, because the secondary carbenium ion on the methylene carbon atom is very unstable [17]. An $\mathrm{S}_{\mathrm{N}} 2$ reaction would mean that the $\mathrm{SH}^{-}$or $\mathrm{H}_{2} \mathrm{~S}$ nucleophile has to react from the inside of a cyclohexane ring on the adamantane surface (Scheme 3) [25]. This reaction is equivalent to that of $\mathrm{SH}^{-}$or $\mathrm{H}_{2} \mathrm{~S}$ with cyclohexylamine with the amine group in equatorial position, which is known to be impossible; a substituent can only react

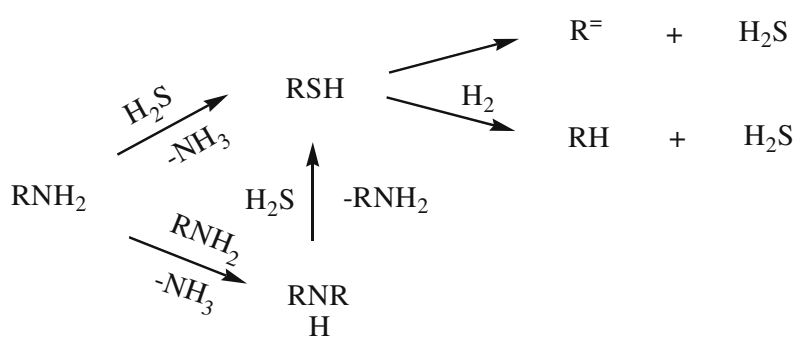

Scheme 2. Primary and secondary formation of an alkanethiol from an alkylamine. 




Scheme 3. $\mathrm{S}_{\mathrm{N}} 2$ reaction of 2-adamantylamine.

when in axial position [17]. We therefore conclude that 2-adamantylamine reacts in the same way as neopentylamine, by a sequence of dehydrogenation-additionelimination-hydrogenation reactions (Scheme 1). 2-Adamantylamine can adsorb with its $\mathrm{C}-\mathrm{N}$ bond parallel to the metal sulfide surface and become dehydrogenated to 2-adamantylimine or to the 2-adamantylimine cation. Addition of $\mathrm{H}_{2} \mathrm{~S}$ and elimination of $\mathrm{NH}_{3}$ leads to 2-thioadamantanone. Similarly, addition of 2-adamantylamine to 2-adamantylimine and elimination of $\mathrm{NH}_{3}$ gives di(2-adamantyl)imine (cf. Scheme 1), which, after addition of $\mathrm{H}_{2} \mathrm{~S}$ and elimination of 2-adamantylamine, gives 2-thioadamantanone as well. Further hydrogenation of 2-thioadamantanone gives 2-adamantanethiol. The high initial selectivity of di(2-adamantyl)imine is in good agreement with this mechanism. The much higher conversion of 2-adamantylamine $\left(73 \%\right.$ at $\left.300{ }^{\circ} \mathrm{C}\right)$ than of neopentylamine $\left(49 \%\right.$ at $340{ }^{\circ} \mathrm{C}$, both at $\tau=9.4 \mathrm{~g} \mathrm{~min} / \mathrm{mol}$ ) is in line with the higher conversion of alkylamines with the amine group attached to a secondary than to a primary carbon atom [15].

\section{3. $\mathrm{HDN}$ of 1-AdNH}

1-Adamantylamine reacted slower than 2-adamantylamine and about as fast as n-alkylamines [3]. Hofmann elimination cannot explain the reaction of 1-adamantylamine because in that case the highly strained adamantene would be formed. 1-Adamantylamine cannot react by a standard $\mathrm{S}_{\mathrm{N}} 2$ reaction either, because a nucleophile cannot approach the reaction center from the rear, through the adamantane cage, as required for a classic organic $\mathrm{S}_{\mathrm{N}} 2$ reaction with Walden inversion [17,18]. An indirect substitution mechanism by means of an iminium or iminium cation intermediate, as in the HDN of neopentylamine and 2-adamantylamine, is not possible either, because 1-adamantylamine does not have an hydrogen atom at the $\alpha$-carbon atom. Since adamantane was a secondary product, also hydrogenolysis cannot explain the HDN of 1-adamantylamine. This is understandable, because hydrogenolysis of the $\mathrm{C}-\mathrm{N}$ bond requires adsorption of both neighboring $\mathrm{N}$ and $\mathrm{C}$ atoms on the catalyst surface and this is sterically impossible for 1-adamantylamine.

An $S_{N} 1$ reaction does not seem possible for 1-adamantylamine either, because the adamantyl cation cannot attain stabilization by flat $\mathrm{sp}^{2}$ hybridization at the bridgehead. Nevertheless, reactions at the bridgehead of adamantane are known to be relatively fast and the salt of the 1-adamantyl cation and $\mathrm{SF}_{6}{ }^{-}$has been prepared. This has been ascribed to stabilization by a flattening of the bridgehead and hybridization between $\mathrm{sp}^{3}$ and $\mathrm{sp}^{2}$ [23]. On the other hand, the $\mathrm{H}_{2} \mathrm{~S}$ pressure has a strong positive influence on the conversion of 1-adamantylamine and this speaks against an $\mathrm{S}_{\mathrm{N}} 1$ reaction. An alternative $\mathrm{NH}_{2}$-SH substitution mechanism of 1-adamantylamine could be an alkyl migration on the metal sulfide surface. For instance, the amine could adsorb at the vacancy on a Mo or Ni atom and then the alkyl group could migrate to a sulfur atom on the neighboring metal atom (Scheme 4). This is similar to schemes suggested by Laine for nucleophilic substitution assisted by metal atoms at the surface of a metal sulfide [26]. It is also in agreement with DFT calculations of a methylamine molecule adsorbed on a vacancy on the Mo edge of a $\mathrm{MoS}_{2}$ crystallite. These calculations showed that the energy barrier for the shift of the methyl group to a neighboring sulfur atom is low [27].

Only 1-adamantanethiol, and no 2-adamantanethiol or 2-adamantylamine, was observed in the reaction of 1adamantylamine, neither were 1-adamantanethiol and 1-adamantylamine observed in the reaction of 2 -adamantylamine. The absence of isomerization is related to Bredt's rule and the absence of elimination of ammonia from adamantylamines and adamantanethiol. It is due to the fact that the isomerization must take place by a transition from the 1-adamantyl to the 2adamantyl carbenium ion. This transition requires that the $2 p_{z}$ orbitals on the neighboring carbon atoms are parallel in the transition state. Because of the rigid cage structure of adamantane, this is extremely difficult [28].



Scheme 4. $\mathrm{NH}_{2}-\mathrm{SH}$ substitution by alkyl migration on the metal sulfide surface. 
The conversion of 1-AdNH $\mathrm{N}_{2}$ increased strongly with increasing $\mathrm{H}_{2} \mathrm{~S}$ pressure, while that of $2-\mathrm{AdNH}_{2}$ increased slightly and that of neopentylamine decreased slightly. This effect is similar to that on the HDN of trihexylamine, dihexylamine, and hexylamine, in which $\mathrm{H}_{2} \mathrm{~S}$ had a slightly positive, nil, and negative effect, respectively [3]. Like in the case of the hexylamines, we believe that for the adamantylamines and neopentylamine the different $\mathrm{H}_{2} \mathrm{~S}$ effects are due to two competing factors. An increased $\mathrm{H}_{2} \mathrm{~S}$ pressure favors the substitution reaction of the amine with $\mathrm{H}_{2} \mathrm{~S}$. Because this is the only possible reaction for 1$\mathrm{AdNH}_{2}, \mathrm{H}_{2} \mathrm{~S}$ has a positive influence on its conversion. 2- $\mathrm{AdNH}_{2}$ and neopentylamine, on the other hand, can also react bimolecularly with other amine molecules and form di(2-adamantyl)amine and dineopentylamine, respectively. These disproportionation reactions are suppressed at higher $\mathrm{H}_{2} \mathrm{~S}$ pressure. This dual influence on the HDN of $2-\mathrm{AdNH}_{2}$ and neopentylamine explains the slightly negative or positive effect of $\mathrm{H}_{2} \mathrm{~S}$.

None of the three thiols resulting from the $\mathrm{NH}_{2}-\mathrm{SH}$ substitution in neopentylamine, 1-adamantylamine, and 2-adamantylamine can react by $\mathrm{H}_{2} \mathrm{~S}$ elimination. Neopentanethiol cannot undergo elimination because of the absence of a $\beta$-H atom and the adamantanethiols cannot form adamantene. This leaves hydrogenolysis as the only reaction pathway. The moderate to low thiol concentrations observed during the HDN reactions of the three amines and the fast reaction of 1-adamantanethiol in the presence of hexylamine demonstrate that the hydrogenolysis is a fast reaction. The hydrogenolysis of the $\mathrm{C}-\mathrm{S}$ bond of the thiol may occur as observed by Curtis and Druker for the reactions of alkyl- and arylthiols in the homogeneous reaction with a $\mathrm{Mo}_{2} \mathrm{Co}_{2}$ cluster [6]. After adsorption of the neopentanethiol or adamantanethiol with the sulfur atom on a Mo or $\mathrm{Ni}$ atom at the metal sulfide surface, the neopentyl and adamantyl groups may react with a hydrogen atom on a neighboring sulfur atom to neopentane and adamantane, respectively. DFT calculations of the hydrogenolysis of methanethiol have shown that this path has a low activation energy [29].

\section{Conclusions}

Neopentylamine reacts to dineopentylamine, dineopentylimine, neopentanethiol, and neopentane at $340{ }^{\circ} \mathrm{C}$, while 2-adamantylamine forms di(2-adamantyl)amine, di(2-adamantyl)imine, 2-adamantanethiol and adamantane with high conversion already at $300{ }^{\circ} \mathrm{C}$. Alkylimines, formed by dehydrogenation of the alkylamines, are intermediates in the formation of the alkanethiols, dialkylimines, and dialkylamines. An alkylimine forms an alkanethiol by addition of $\mathrm{H}_{2} \mathrm{~S}$, elimination of ammonia, and hydrogenation of the thi- oketone. Addition of another alkylamine molecule to an alkylimine forms a geminal diamine intermediate, which after elimination of ammonia gives the dialkylimine. Hydrogenation of the dialkylimine gives the dialkylamine.

Neopentane and adamantane were secondary products in the HDN of neopentylamine and 2-adamantylamine, respectively. These alkanes were formed by hydrogenolysis of the corresponding alkanethiols, formed by substitution of the alkylamines and dialkylamines with $\mathrm{H}_{2} \mathrm{~S}$. The secondary character of neopentane and adamantane demonstrates that direct hydrogenolysis of neopentylamine to neopentane does not take place over sulfided NiMo catalysts.

Even though E1 and E2 reactions and a classic $\mathrm{S}_{\mathrm{N}} 2$ reaction cannot take place, 1-adamantylamine reacted to 1 -adamanethiol at $300{ }^{\circ} \mathrm{C}$. This reaction might be due to an $\mathrm{S}_{\mathrm{N}} 1$ reaction or to adsorption of the amine at a surface vacancy, followed by a shift of the adamantyl group to a neighboring sulfur atom.

\section{References}

[1] M.J. Girgis and B.C. Gates, Ind. Eng. Chem. Res. 30 (1991) 2021.

[2] B.C. Wiegand, C.M. Friend, P. Uvdal and M.E. Napier, Surf. Sci. 355 (1996) 311.

[3] Y. Zhao, P. Kukula and R. Prins, J. Catal. 221 (2004) 441.

[4] M. Houalla, N.K. Nag, A.V. Sapre, D.H. Broderick and B.C. Gates, AIChE J. 24 (1978) 1015.

[5] J. Mijoin, G. Perot, F. Bataille, J.L. Lemberton, M. Breysse and S. Kasztelan, Catal. Lett. 71 (2001) 139.

[6] M.D. Curtis and S.H. Druker, J. Am. Chem. Soc. 119 (1997) 1027.

[7] N. Nelson and R.B. Levy, J. Catal. 58 (1979) 485.

[8] H. Schulz, M. Schon and N.M. Rahman, Stud. Surf. Sci. Catal. 27 (1986) 201.

[9] C. Moreau, C. Aubert, R. Durand, N. Zmimita and P. Geneste, Catal. Today 4 (1988) 117.

[10] M. Jian, F. Kapteijn and R. Prins, J. Catal. 168 (1997) 491.

[11] Y. Zhao, J. Czyzniewska and R. Prins, Catal. Lett. 88 (2003) 155.

[12] J.L. Portefaix, M. Cattenot, M. Guerriche, J. Thivolle-Cazat and M. Breysse, Catal. Today 10 (1991) 473.

[13] L. Vivier, V. Dominguez, G. Perot and S. Kasztelan, J. Mol. Catal. 67 (1991) 267.

[14] Y. Zhao and R. Prins, J. Catal. 222 (2004) 532.

[15] Y. Zhao and R. Prins, J. Catal. 229 (2005) 213.

[16] P. Kukula, A. Dutly, N. Sivasankar and R. Prins, J. Catal. 236 (2005) 14.

[17] M.B. Smith and J. March, Advanced Organic Chemistry, 5 ed.(Wiley, New York, 2001).

[18] J. Clayden, N. Greeves, S. Warren and P. Wothers, in: Organic Chemistry (Oxford Univ. Press, 2001).

[19] G. Meitzner, W.J. Mykytka and J.H. Sinfelt, J. Catal. 98 (1986) 513.

[20] Triyono and R. Kramer, Appl. Catal. A 100 (1993) 145.

[21] N. Sivasankar and R. Prins, Catal. Today, submitted for publication.

[22] E.L. Tae, Z. Zhu and M.S. Platz, J. Phys. Chem. A 105 (2001) 3803.

[23] G.A. Olah, Cage Hydrocarbons (Wiley, New York, 1990).

[24] P.v.R. Schleyer and R.D. Nicholas, J. Am. Chem. Soc. 83 (1961) 2700 . 
[25] J.L. Fry, C.J. Lancelot, L.K.M. Lam, J.M. Harris, R.C. Bingham, D.J. Raber, R.E. Hall and P.v.R. Schleyer, J. Am. Chem. Soc. 92 (1970) 2538.

[26] R.M. Laine, Catal. Rev. -Sci. Eng. 25 (1983) 459.

[27] T. Todorova and R. Prins, unpublished results.
[28] D.M. Brouwer, in Chemistry and Chemical Engineering of Catalytic Processes, R. Prins and G.C.A. Schuit (eds) (SythofNoordhof, Alphen, 1980), p. 137.

[29] T. Todorova, Th. Weber and R. Prins, J. Catal. 236 (2005) 190. 